\title{
PERENCANAAN MASTERPLAN PASAR BATAN KENDAL KELURAHAN SESETAN, DENPASAR
}

\author{
Oleh: \\ I Wayan Wirya Sastrawan ${ }^{(1)}$ I Gede Surya Darmawan ${ }^{(2)}$ \\ 1) Dosen Jurusan Program Studi Arsitektur, Fakultas Teknik \\ Universitas Warmadewa, Jl. Terompong No. 24 Denpasar - Bali, Indonesia \\ E-mail : wayanwiryasastrawan@gmail.com \\ ${ }^{2)}$ Dosen Jurusan Program Studi Arsitektur, Fakultas Teknik \\ Universitas Warmadewa, Jl. Terompong No. 24 Denpasar - Bali, Indonesia \\ E-mail : gdsuryadarmawan@gmail.com
}

\begin{abstract}
A B S T RA K
Kebutuhan Warga Banjar Suwung Batan Kendal akan dana dalam menyelenggarakan berbagai kegiatan ritual adat keagamaan yang harus mereka selenggarakan setiap tahunnya merupakan salah satu faktor awal munculnya ide untuk membangun usaha bersama berupa pasar. Pasar Batan Kendal yang dibangun warga banjar sejak tahun 1996 kini dalam kondisi tidak layak pakai. Dengan kondisi pasar seperti itu warga banjar dan pengelola pasar sudah melakukan perombakan pasar secara bertahap mulai tahun 2016 yang juga melibatkan pihak Universitas Warmadewa sebagai mitra pendamping. Sayangnya, perombakan tahap pertama itu belum mencakup keseluruhan areal pasar dan hanya areal depan pasar yang dapat dilakukan perombakan. Tentunya keadaan ini memunculkan permasalahan baru seperti: terjadinya kesenjangan antara pedagang yang mendapatkan fasilitas fisik bangunan baru dengan pedagang yang masih dengan fasilitas bangunan lama. Dari keseluruhan permasalahan mitra tersebut maka solusi yang dapat diberikan yaitu dengan mendampingi dan secara bersama melakukan Perencanaan dan Perancangan Master Plan Pasar Batan Kendal. Dalam penyusunan master plan ini tentunya akan melibatkan warga banjar, penglelola, dan para pedagang pasar mulai dari tahapan survey, pencarian informasi kebutuhan pengunan/pemilik dan data lapangan, penyusunan alternative desain, diskusi alternative desain, hingga pada penyusunan desain akhir. Dari program ini terdapat target luaran yang ingin dicapai terutama untuk menyelesaikan masalah prioritas mitra adalah dokumen berupa gambar Master Plan Pasar Batan Kendal sekaligus dijadikan sebagai dokumen pendukung proposal penggalian dana pembangunan pasar. Kemudaian bentuk keberlanjutan kerjasama antara mitra ketika program ini berakhir adalah dengan mendampingi mitra ketika akan dilanjutkan pada tahap pelaksanaan.
\end{abstract}

Kata kunci : perencanaan, perancangan, masterplan, pasar

\section{ANALISA SITUASI}

Selain sebagai wadah penyedia kebutuhan pokok, pasar juga dapat menggerakan dan meningkatkan perputaran perekonominan masyarakat disekitarnya terlebih lagi dapat memberikan peluang lapangan pekerjaan baru bagi masyarakatnya. Bagi sekelompok masyarakat pasar sendiri dapat menjadi aset menjanjikan yang memberikan sumber penghasilan dalam bentuk jasa pengelolaan dan penyedia fasilitas pasar itu sendiri.

Melihat potensi dari penyelenggaraan pasar inilah yang memunculkan semangat warga Banjar Suwung Batan Kendal, Kelurahan Sesetan membangun sebuah pasar di wilayah mereka. Usaha ini dilakukan warga 
mengingat kebutuhan warga akan dana dalam menyelenggarakan kegiatan ritual adat keagamaan di pura yang harus mereka selenggarakan setiap tahunnya.

Maka jadilah melalui Paruman Agung (rapat besar warga) Banjar Suwung Batan Kendal menyepakati dan pembangunan pasar ini yang dimulai dari tahun 1996 hingga rampung pada tahun 1997, sekaligus diplaspas (peresmian dalam bentuk upacara adat tradisioanal Hindu Bali) dan diresmikan dengan nama Pasar Batan Kendal. Namun kini pastinya kualiatas desain dan bahan bangunan pasar sudah tidak layak untuk dapat difungsikan hingga.

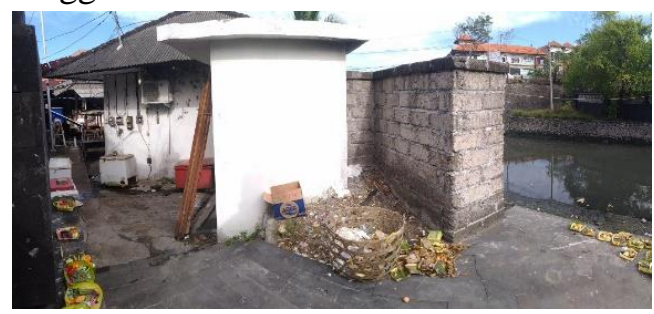

Gambar 1. Batas berupa muara sungai dan halaman pasar berada di bawah dinding sungai.

Sumber: Dukumentasi , 2018

Untuk mengembalikan kelayakan pasar ini, maka warga warga Banjar Suwung Batan Kendal beserta Pengelola Pasar Batan Kendal kembali berupaya untuk merenovasi dan mendesain ulang pasar ini. Upaya ini sudah dimulai secara bertahap sejak pertengahan tahun 2015 dengan pendampingan pihak ahli yaitu Universitas Warmadewa khususnya Jurusan Teknik Arsitektur.

Dengan kondisi saat ini Pasar Batan Kendal sudah kembali dengan wajah baru namun arel belakang pasar masih dalam kondisi lama. Kondisi tersebut tentu memunculkan beberapa permasalahan, seperti kesenjangan fasilitas prasarana yang diberikan kepada pedagang dan pembeli di areal belakang. '

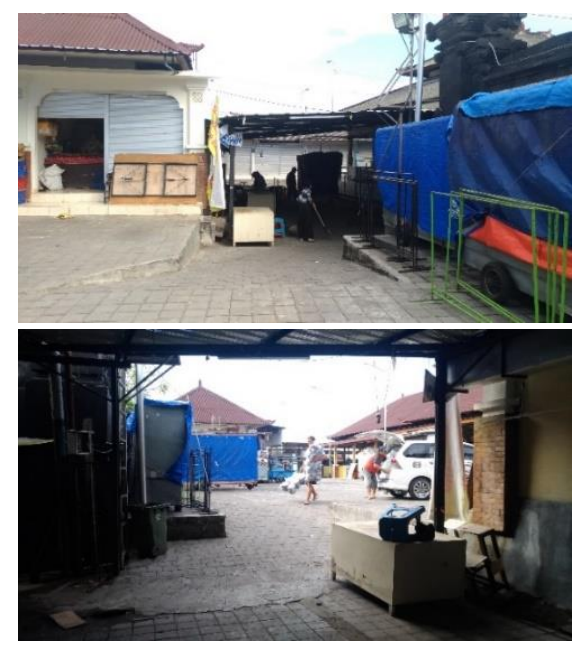

Gambar 2. Foto perbedaan ketinggian permukaan halaman pasar Sumber:

Dukumentasi, 2018

Melihat permasalahan yang dihadapi saat ini maka kembali Universitas Warmadewa bersama warga banjar dan pengelola pasar melanjutkan perencanaan desain tahap berikutnya. Dari semua permasalahan dan kondisi Pasar Batan Kendal tersebut memerlukan penyelesaian berupa Master Plan Pasar Batan Kendal. Nantinya gambar ini dapat dijadikan sebagai dasar pembuatan RAB dalam proposal pengalian dana, pelaksanaan pembangunan, dan proses pemeliharaan/perawatan bangunan nantinya.

\section{SOLUSI}

Berdasarkan permasalahan yang ada dilapangan maka solusi yang dapat mengatasinya adalah dengan melakukan Perencanaan dan Perancangan Master Plan Pasar Batan Kendal. Secara teknis solusi ini dapat dilakukan melalui peran aktif warga banjar, pengelola pasar, dan pedagang memberikan masukan pada diskusi serta menguraikan apa yang dibutuhkan dan perlu dikembangkan terutama pada bagian fisik pasar. Kemudian pada tahapan selanjutnya pihak Universitas Warmadewa sebagai mitra pendamping akan mengembangkan desain perencanaan penataan Pasar Batan Kendal 
berdasarkan masukan dan diskusi, sehingga secara bertahap perencaaan fisik pasar dapat dilengkapi dan diselesaikan demi kelancaran kegiatan di Pasar Batan Kendal.

\section{METODE PELAKSANAAN}

Adapun bentuk kegiatan pengabdian kepada masyarakat ini diuraikan kedalam tahapan kegitaan sebagai berikut:

\section{Survei dan Pengumpulan Data}

Melakukan observasi lapangan untuk memperoleh data lengkap dilapangan. Data yang dikumpulakan dapat berupa foto-foto eksisting, dimensi site dan bangunan eksisting Pasar Batan Kendal. Tentunya data yang terpenting adalah keinginan dan harapan dari mitra yang ditampung memalui wawancara, sehingga dapat dijadikan acuan dalam proses perencanaan selanjutnya.

\section{Desain Alternatif}

Pendekatan desain kelengkapan bangunan maupun landscape pasar akan mengacu pada permintaan mitra yang tentunya juga akan disesuaikan dengan kondisi eksisting. Desain ini akan dituangkan kedalam bentuk gambar 2D dan 3D untuk memudahkan mitra untuk memahami maksud dari rancangan.

\section{Presentasi dan Konsultasi dengan Mitra (Focus Goup Discussion/ FGD)}

Diharapkan melalui FGD ini mitra dapat mendapatkan gambaran fisik pasar yang direncanakan, dan terpenting adalah masukan-masukan dari mitra terkait desain demi tercapainya desain sesuai keinginan bersama.

\section{Pemecahan Masalah}

Dalam pengabdian kepada masyarakat ini semua masalah akan dapat dicarikan solusi bila ada kerjasama yang baik dengan pihak mitra. Kerjasama yang baik ini dapat dilakukan dengan keterlibatan langsung pihak mitra dalam setiap proses kegiatan, karena pentingnya keterbukaan, pengawasan, dan masukan dari mitra akan mentukan kulaitas desain perencanaan dan penataan pasar ini. Mitra sebagai pengguna tentunya sangat memahami betul setiap permasalah, kebutuhan, dan kekurangan yang ingin dilengkapi pada pasar ini.

\section{HASIL KEGIATAN}

\section{A. Keadaan Eksisting dan Pengukuran Pasar Batan Kendal}

Kondisi eksisting Pasar Kendal terbagi menjadi dua areal terpisah yang dihubungkan dengan satu akses dengan posisi entrance yang sama. Pada pemugaran tahap pertama hanya dapat menyelesaikan areal depan pasar yang terdiri dari areal kios pakaian, sembako, peralatan rumah tangga, dan los sarana persembahyangan (Upakara). Kondisi fisik areal depan pasar ini sudah sangat layak dengan perencanaan yang sangat baik terutama dalam sisi desaian tataruang, fungsi, dan tampilan bangunan.

Sedangkan diareal belakang pasar masih dengan kondisi eksisting awal pembangunan pasar pada tahun 1996, yang terdiri dari kios pakaian dan los penjualan daging/ikan. Tentunya kondisi fisik sangat berbeda dengan areal depan pasar dengan kondisi fisik baru. Terlebih lagi perbedaan ketinggian permukaan tanah di areal depan pasar yang mengalami peninggian menyebabkan perbedaan terjadi selisih ketinggian permukaan tanah mencapai $80 \mathrm{~cm}$. 


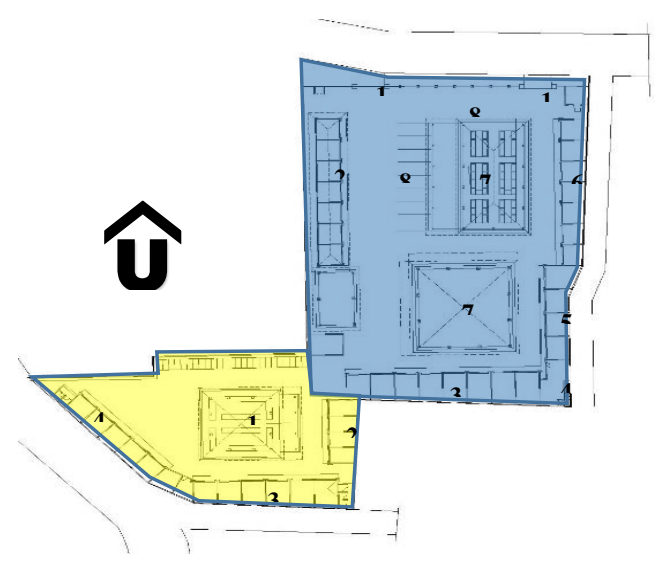

Gambar 3. Lay Out Eksisting Pasar Sumber : Dokumentasi 2018

Keterangan Gambar:

A. Areal Depan Pasar

1. Entrance

2. Kios Sembako/pakaian

3. Kios Sembako

4. Kantor Koperasi

5. Kios Sembako

6. Kios pakaian/peralatan rumah tangga

7. Los Sarana Upakara / sayuran

8. Parker

B. Areal Belakang Pasar

1. Los Daging/ikan

2. Kios Pakaian

3. Kios Pakaian

4. Kantor Pengurus Pasar

\section{B. Proses dan Hasil Desain Pasar Batan Kendal}

Pada dasarnya perencanaan sebuah pasar tentunya sudah ada aturan-aturan yang mengikat terutama dari tata zonasi dan jaringan utilitas baik dari sisi bangunan dan penataan keruangan. Sehingga hal yang mutlak terjadi adalah keselarasan bangunan lama dan paru pada pasar ini agar secara fungsi, aktifitas dan utiltas bangunan dapat beroprasi dengan baik tanpa mengganggu aktivitas yang terjadi dalam pasar. Maka dalam perencaaan renovasi bangunan di areal belakang pasar harus dilakukan dengan perencaan yang matang. Tentunya untuk menghasilkan perencaan yang baik ini harus memalui beberpa tahapan yang https://ejournal.warmadewa.ac.id/index.php/wicaksana

tentunya harus melibatkan pengguna, pemilik, dan perencana sesuai kompetensinya masingmasing.

\section{B.1. Focus Group Discution (FGD) I}

Berdasarkan surat permohonan pendampingan dari mitra selanjutnya dilakukan diskusi awal dengan mitra sekaligus Pemilik dan Pengelola Pasar pada tanggal 20 Agustus 2018, disepakati beberapa ide dan masukan pada perencanaan desain pasar. Beberapa masukan dan ide yang disepakati diantaranya adalah perencanaan focus penyelesain masalah singkronisasi jaringan utulitas dan desain areal depan dengan belakang. Selain itu disepakati pula melakukan peninggian permukaan tanah setingi areal depan, jumlah kios dan los minimal sama atau bertambah maksimal, penambahan fasilitas penambatan gerobak pedagang pasar senggol, dan pemindahan areal kantor pengurus pasar ke lantai dua bangunan.
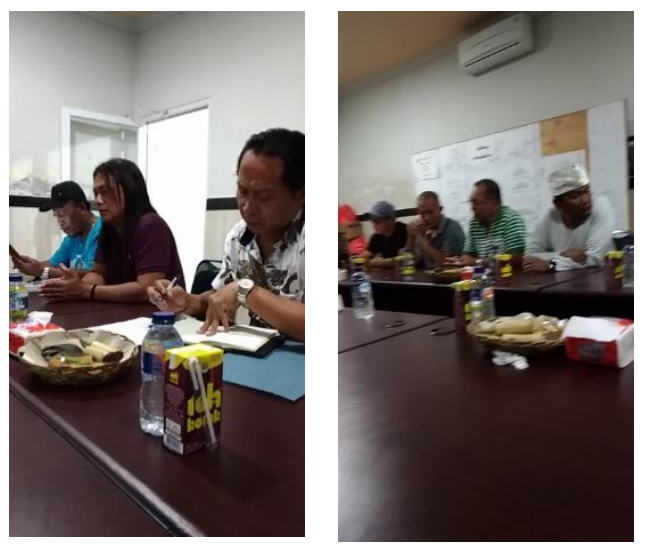

Gambar 4. Kegiatan FGD I

Sumber : Dokumentasi 2018

\section{B.2. Pengukuran Kondisi Eksisting Pasar Batan Kendal}

Setalah dilakukan FGD I dan menghasilkan beberapa keputusan dan arahan maka tim baru dapat bergerak dengan tahap pertama melakukan pengukuran kondisi eksisting pasar batan Kendal. Dalam pengukuran diketahui batasan-batasan site yang akan direncanakan, perbedaan ketinggian permukaan tanah, jaringan utilitas areal depan pasar yang nantinya akan disambungkan 
keareal belakang. Data eksisting ini kemudian yang akan disalain kedalam gambar $\mathrm{Cad}$ (gambar 3) dan selanjutnya akan dilakukan perencanaan sesuai hasil FGD I.

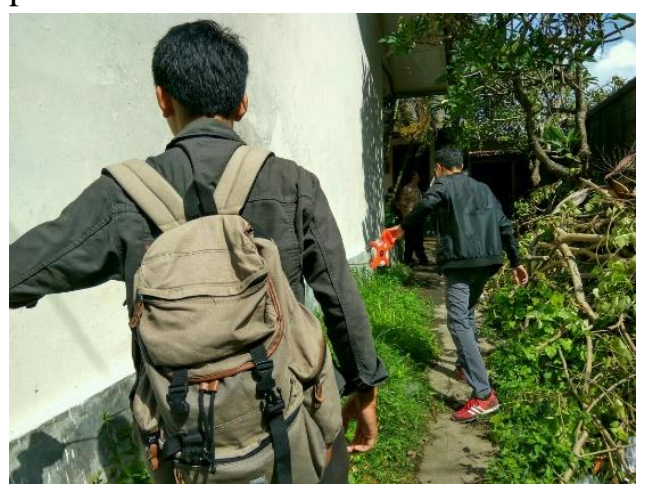

Gambar 5. Pengukuran Eksisiting Sumber :

Dokumentasi 2018

\section{B.3. Proses dan Hasil Desain Pasar Batan Kendal}

Berdasarkan hasil FGD I maka focus perencanaan dilakukan pada areal belakang pasar. Tahap selanjutnya yang dilakukan tim dalah melakukan pemrograman kebutuhan dan pemanfaatan site. Untuk menghasilkan pemrograman kebutuhan dilakukan dengan mendata kembali jumlah kios dan los eksisting yang ada untuk ditampung kembali dalam perencanaan. Diketahui jumlah kios eksisting 14 unit, los 20 unit, toilet 3 uit, Kantor pengelola dan ruang rapat. Hasil ini kemudian dimasukan kembali dalam perencaaan baru pada site dengan pemaksimalan penambahan kios dan los yang memungkinkan untuk dilakukan. Dalam perencanaan dan pengolahan site menghasilkan jumlah kios tetap 14 unit namun dengan dimensi yang lebih besar sehinga dapat dijual lebih mahal, los dapat ditata mencapai 25 unit, Kantor Pengelola dapat dirinci menjadi Ruang Pengelola pasar, Pengurus Pasar, Lobby kantor, dan ruang rapat yang semua berada di lantai dua kios. Hasil FGD I juga mengharapkan terdapat areal terbuka yang dapat dijadikan sebagai tempat parker dari gerobak pedang kamar senggol ini dapat terfasilitas. Berdasarkan pertimbangan tim perencana maka ditambahkan fasilitas berupa ruang genset sebagai daya cadangan bila sewaktu-waktu listrik padam. Adapun hasil perencanaan dapat dilihat pada gambar dibawah.

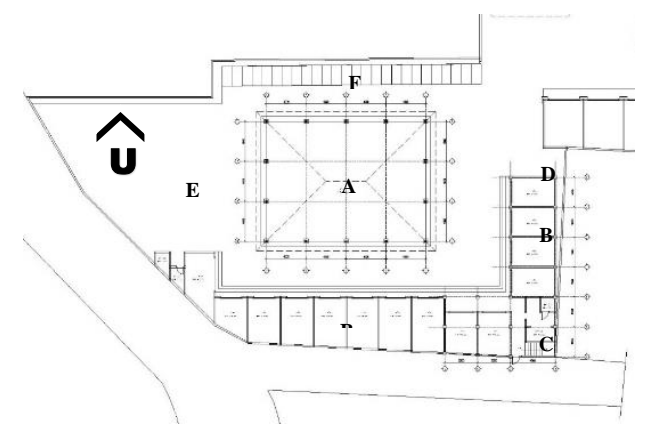

Gambar 6. Lay Out Lantai 1 Sumber :

Dokumentasi 2018

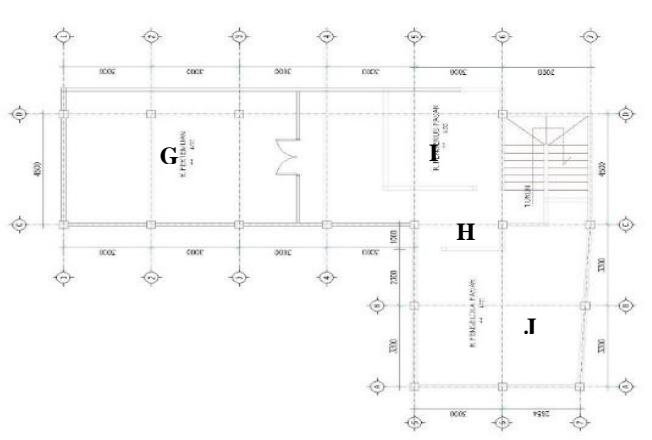

Gambar 7. denah Lantai 2

Sumber : Dokumentasi 2018

Keterangan Gambar:
A. Los
B. Kios
C. Toilet, Tangga
D. Ruang Genset
E. Parkir Gerobak
F. Parkir
G. Ruang Rapat
H. Lobby
I. Pengurus Pasar
J. Pengelola Pasar

\section{B.4. Focus Group Discution (FGD) II}

Ketika konsep desaian penataan ruang sudah rampung berdasarkan hasil masukan FGD I maka tim pengabdian mengajukan kembali untuk diadakan FGD II untuk mendapat persetujuan terkait konsep desain agar dapat dilanjutkan pada tahap 
penggambaran detail. Maka jadilah dilaksanakan FGD II pada tanggal 8 September 2018 di Bale Banjar Suwung Batan Kendal. Dalam FGD II kali ini turut diundang beberpa perwakilan pedagang dan warga Banjar Suwung Batan Kendal selaku pemilik pasar dengan harapan adanya masukan lebih lanjut terkait desain perencanaan. Hasil FGD II ini menyimpulkan desain yang direncanakan tim sudah maksimal dan dapat disetujui oleh mitra untuk dapat dilanjutkan ketahap berikutnya.

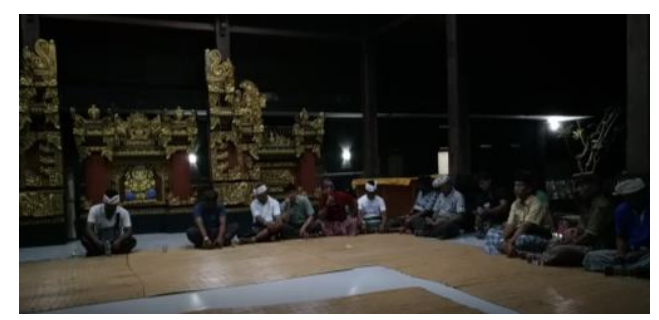

Gambar 8. Kegiatan FGD II

Sumber : Dokumentasi 2018

\section{B.5. Pengembangan Desain dan Penyusunan Dokumen Gambar Pra Rancangan}

Melalui FGD II telah disepakati desain perencanaan pasar yang tim pengabdian ajukan, maka tahap selanjutnya adalah penyusunan gambar pra rancangan berupa denah, tampak, potongan, Site Plan, dan 3D. Dalam proses ini dilakukan pendimensian yang akurat terkait dimensi denah, tampak, dan lay out dari masing-masing unit bangunan agar nantinya dapat teraplikasi dengan tepat dilapangan. Dalam proses penyusunan dokumen gambar pra rancangan ini melibatkan dua mahasiswa untuk mempercepat proses pegambaran dan dapat dilaporkan dalam laporan kegiatan pengabdian kepada masyarakat.

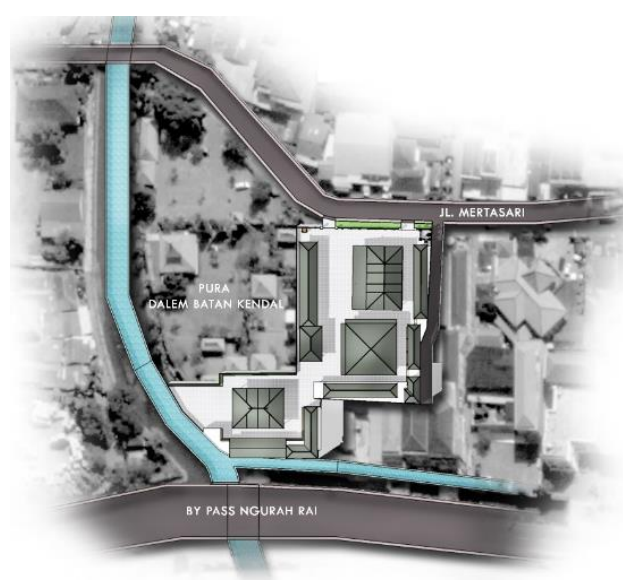

Gambar 9. Gambar Site Plan Sumber : Dokumentasi 2018

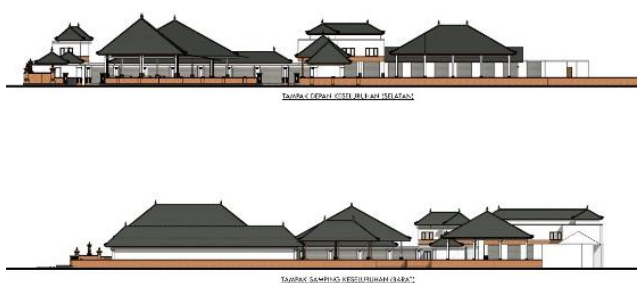

Gambar 10. Tampak Site Sumber : Dokumentasi 2018

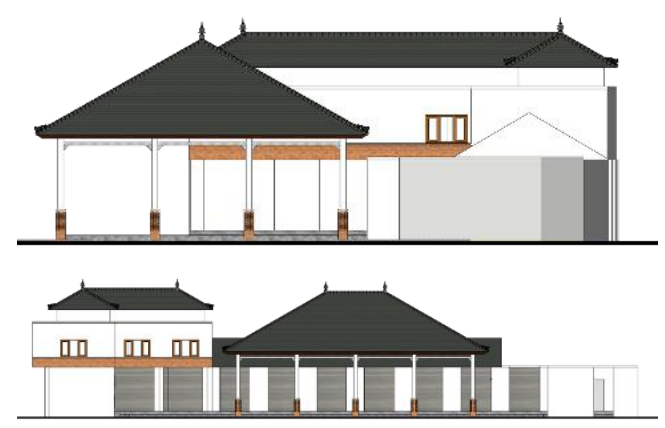

Gambar 11. Tampak Los dan Kios Sumber : Dokumentasi 2018

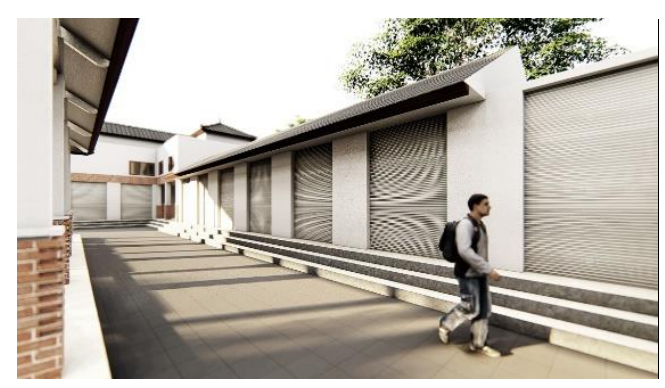

Gambar 12. 3D Los dan Kantor Sumber : Dokumentasi 2018 


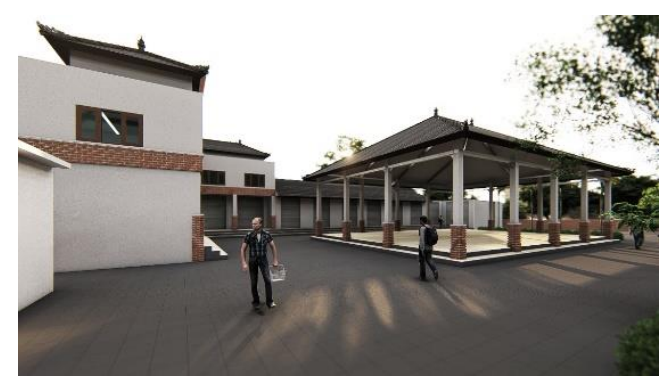

Gambar 13. 3D Los dan Kantor.

Sumber : Dokumentasi 2018

\section{B.6. Focus Group Discution (FGD) III}

Setelah seluruh dokumen gambar jadi, tim pengabdian mengajukan kembali untuk diadakan FGD III pada tangal 2 Oktober 2018 dengan agenda penyerahan dan presentasi akhir Desain Master Plan dan Pembangunan Tahap Kedua Pasar Batan Kendal. Kegiatan ini disambut baik oleh mitra dan pada kesempatan itu pula dari mitra mengundang langsung perwakilan rakyat (DPRD Kota Denpasar) yang nantinya diharapkan dapat mengawal proposal Pembangunan Tahap Kedua Pasar Batan Kendal yang diajukan. Dalam FGD III tersebut mitra menyambut baik hasil Desain yang diserahkan didkukung pula oleh anggota dewan yang hadir untuk segera dibuatkan proposal untuk diajukan, sehingga dapat dianggarkan dana atau di ajukan pada tahun 2019. Dengan hasil FGD III ini kembali mitra memohon pendampingan tahap selanjutnya sampai proposal yang diharapkan dapat terwujud dan diajukan.

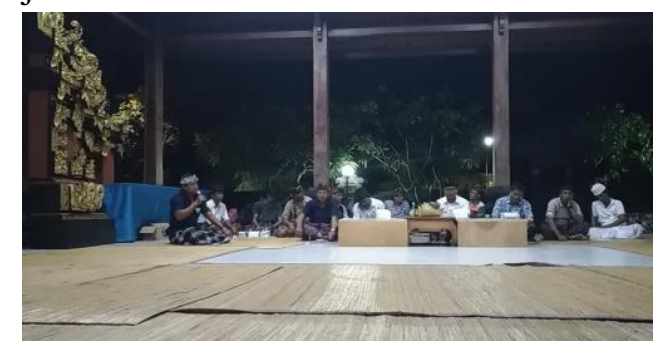

Gambar 14. Kegiatan FGD III

Sumber : Dokumentasi 2018

\section{Pelaporan Kegiatan Pengabdian Kepada Masyarakat}

Mengingat pelaporan kegiatan pengabdian ini sudah melebihi pada batas waktunya maka pelaporan kegiatan ini harus segera dilaporkan dan dapat disampaikan bahwa secara garis besar Perencanaan Master dan Pembangunan Pasar Batan Kendala Tahap kedua sudah rampung sesuai dengan target capain yang disampaikan diawal. Namun perkembangan yang terjadi dilapangan nampaknya pengabdian ini masih tetap berjalan, mengingat mitra masih membutuhkan pendampingan terutama dalam penyusunan Rencana Anggaran Biaya (RAB) dan proposal Pembangunan Tahap kedua Pasar Batan Kendal.

Tidak lepas sampai disana juga, nantinya jika pembangunan pura dapat terlaksana maka kewajiban tim pula melakukan pendampingan terutama dalam strategi manajeman kontruksi serta pengawasan dilapangan. Sehingga apa yang direncanakan tim bersama Mitra dapat terlaksana dan terbangun sesuai harapan. Tentunya penyusuanan RAB, Gambar Kerja di lapangan, dan Pendampingan Kontruksi ini tidak dapat diprediksi waktunya mengingat ini kan sangat tergantung dari dana dan sumber dana yang diperoleh mitra.

\section{KESIMPULAN \& SARAN}

Sesuai dengan hasil kegiatan dan pembahasan di BAB $\mathrm{V}$ maka dapat ditarik kesimpulan sebagai berikut :

1. Perencanaan Master Plan dan Pembangunan Tahap Kedua Pasar Batan Kendal yang direncanakan akan menyesuaikan dengan kondisi fisik eksisting di areal depan pasar untuk diselaraskan.

2. Perencanaan Master Plan dan Pembangunan Tahap Kedua Pasar Batan Kendal ini menerapkan tata nilai sesuai peruntuknnya yaitu Pasar itu sendiri yang dimulai dari zonasi kerungan hinga ke bangunannya. Maka dari itu Perencanaan Master Plan dan Pembangunan Tahap Kedua Pasar Batan Kendal tidak terlepas dari kebutuhan, kenyamanan, dan kemananan pengguna lainnya. 
https://ejournal.warmadewa.ac.id/index.php/wicaksana

3. Perencanaan fisik estetika, ornament, dan material bangunan pasar menggunakan gaya atau tampilan bangunan di areal depan pasar yaitu bagian atap menggunakan Ondulin, dinding finishing cata dan tempelan bata pres, dan lantai kramik. 